NBER WORKING PAPER SERIES

\title{
ENTRY AND COMPETITION IN LOCAL HOSPITAL MARKETS
}

\author{
Jean M. Abraham \\ Martin S. Gaynor \\ William B. Vogt \\ Working Paper 11649 \\ http://www.nber.org/papers/w11649
NATIONAL BUREAU OF ECONOMIC RESEARCH
1050 Massachusetts Avenue
Cambridge, MA 02138
September 2005

\begin{abstract}
We wish to thank Paul Gertler, Gautam Gowrisankaran, Mark Manuszak, Carol Simon, Jonathan Skinner, Doug Wholey, participants in sessions at the 1999 American Economic Association meetings and the 2001 International Health Economics Association conference, the editor, and two anonymous referees for helpful comments. The views expressed herein are those of the author(s) and do not necessarily reflect the views of the National Bureau of Economic Research.

(C2005 by Jean M. Abraham, Martin S. Gaynor and William B. Vogt. All rights reserved. Short sections of text, not to exceed two paragraphs, may be quoted without explicit permission provided that full credit, including () notice, is given to the source.
\end{abstract}


Entry and Competition in Local Hospital Markets

Jean M. Abraham, Martin S. Gaynor and William B. Vogt

NBER Working Paper No. 11649

September 2005

JEL No. I1, L1, L8

\begin{abstract}
$\underline{\text { ABSTRACT }}$
There has been considerable consolidation in the hospital industry in recent years. Over 900 deals occurred from 1994-2000, and many local markets, even in large urban areas, have been reduced to monopolies, duopolies, or triopolies. This surge in consolidation has led to concern about competition in local markets for hospital services. We examine the effect of market structure on competition in local hospital markets -- specifically, does the hardness of competition increase with the number of firms? We extend the entry model developed by Bresnahan and Reiss to make use of quantity information, and apply it to data on the U.S. hospital industry. In the hospital markets we examine, entry leads to a quick convergence to competitive conduct. Entry reduces variable profits and increases quantity. Most of the effects of entry come from having a second and a third firm enter the market. The fourth entrant has little estimated effect. The use of quantity information allows us to infer that entry is consumer-surplus-increasing.
\end{abstract}

Jean M. Abraham

Division of Health Services Research and

Policy

School of Public Health

University of Minnesota

Mayo Mail Code 510

420 Delaware Street SE

Minneapolis, MN 55455

abrah042@umn.edu

Martin S. Gaynor

Heinz School of Public Policy and

Management

Carnegie Mellon University

5000 Forbes Avenue

Pittsburgh, PA 15213

and NBER

mgaynor@andrew.cmu.edu
William B. Vogt

Heinz School of Public Policy and

Management

Carnegie Mellon University

5000 Forbes Avenue

Pittsburgh, PA 15213

and NBER

wilibear@andrew.cmu.edu 


\section{Introduction}

Throughout the United States, consolidation in the hospital industry is altering the local market structure for hospital services. During the second half of the 1990s, a wave of hospital consolidation occurred in the United States. One source puts the total number of hospital mergers from 1994-2000 at over 900 deals (Jaklevic, 2002, and www.levinassociates.com), on a base of approximately 6,100 hospitals. Many of these mergers have occurred in small markets, thereby resulting in merger to monopoly. Even some large urban markets such as Boston, Minneapolis, and San Francisco are now dominated by two to three large hospital systems. Not surprisingly, many health plans have complained about rising prices as a result of these consolidations (Lesser and Ginsburg, 2001).

This surge in consolidation activity has led to concern about the effects of this consolidation on competition in local markets for hospital services. The federal antitrust enforcement agencies have brought challenges in a number of cases against hospitals seeking to merge. The courts, however, have ruled against the antitrust enforcement agencies on every hospital merger case tried in the last decade (Gaynor and Vogt, 2000).

There have been a number of studies which have examined the relationship between hospital market structure and performance (e.g., Dranove et al., 1993; Connor et al., 1998; Krishnan, 2001; Dranove and Ludwick, 1999). The vast majority of these studies find a positive association between concentration and price or price-cost margins. ${ }^{1}$ There have also been a smaller number of studies which examine the relationship between concentration and hospital quality or service offerings (e.g., Dranove et al., 1992; Kessler and McClellan, 2000; Volpp and Waldfogel, 2000). There is no clear pattern in the results of these studies: some find that concentration is associated with lower quality, while others do not.

While these studies have proved very valuable by uncovering consistent patterns in the

\footnotetext{
${ }^{1}$ For exceptions see Lynk (1995); Lynk and Neumann (1999).
} 
data, they are subject to the usual criticism that it is very hard to know if "StructureConduct-Performance" (SCP) studies identify competition (Schmalensee, 1989; Bresnahan, 1989; Gaynor and Vogt, 2000). Bresnahan and Reiss (1991) have developed a method for examining the effect of market structure on competition that is not subject to the problems associated with the SCP approach. The Bresnahan and Reiss (BR) method uses a simple, general entry condition to model market structure. The intuition is that if the population (per-firm) required to support a given number of firms in a market grows with the number of firms then competition must be getting tougher, thereby shrinking profit margins and requiring a larger population to generate the variable profits necessary to cover entry costs. Thus, the key data for this method are market structure and population, which are commonly available and accurately measured.

In particular, the BR method does not require data on price-cost margins or on prices. The former are commonly considered to be subject to biased measurement. As in many industries, buyers (insurers) in the hospital industry are able to negotiate discounts from list prices (called charges), and, although list prices are commonly observable, transaction prices are not..$^{2}$

In this paper we augment the BR approach to incorporate the use of quantity data and apply it to local markets for hospital services. This augmented approach takes advantage of the additional information contained in quantity, without imposing restrictions significantly beyond those implied by the original approach. Further, it allows for qualitative welfare inference. If quantity increases with entry, consumers are better off. If the entry of an additional firm is not accompanied by any increase in quantity, however, then it cannot be social welfare enhancing, since it carries with it additional fixed costs (Berry and Waldfogel, 1999; Mankiw and Whinston, 1986). Our approach allows us to test for whether entry

\footnotetext{
${ }^{2}$ An alternative approach to the BR method which avoids the problems associated with SCP is structural modeling of demand and price setting by firms (Bresnahan, 1989; Berry et al., 1998). This approach requires more assumptions to put the necessary structure on the problem. It also does not readily lend itself to an examination of the relation between market structure and competition.
} 
benefits consumers or is purely wasteful. ${ }^{3}$ This approach extends the empirical literature in industrial organization on evaluating the determinants and effects of entry ${ }^{4}$ by adding to the relatively scarce empirical evidence and proposing a simple extension of the BR method for industries that possess good quantity data.

The results from our estimation are striking. In the hospital markets we examine, entry toughens competition very quickly. Indeed, most of the effects of entry come from having a second and a third firm enter the market. The entry of a fourth has relatively little additional effect. Further, quantity is increasing in the number of firms, implying that entry is beneficial to consumers.

Two recent papers are related to ours. In a closely related paper estimating entry into US broadcast radio markets, Berry and Waldfogel (1999) also extend the BR approach. In addition to data on market structure, Berry and Waldfogel employ data on market shares and on prices. This allows them to make inferences about the efficiency of free entry in the radio broadcasting industry. Our approach is similar to that of Berry and Waldfogel in that we also use data on quantity to augment the BR approach. We do not, however, use data on prices, for the reasons given above. This means that our ability to make welfare inferences is more limited.

Genesove (2004) is another recent paper on entry. Genesove examines possible explanations for the striking reduction in the number of cities in the U.S. with at least two daily newspapers. In particular, he uses an interesting implementation of the BR approach to make inferences about the toughness of competition. Genesove also eschews demand estimation and looks at quantity in some of his analyses, but this is complementary to his entry estimates, as opposed to estimating a joint model of market structure and quantity.

\footnotetext{
${ }^{3}$ We cannot test for socially inefficient entry in general. That requires evaluating the benefits of increased quantity from entry against the fixed costs. To do so would require the use of price data - precisely what we are trying to avoid.

${ }^{4}$ See, for example, Bresnahan and Reiss (1991); Berry (1992); Berry and Waldfogel (1999); Scott Morton (1999); Davis (2002).
} 
We also share in common with both Berry and Waldfogel (1999) and Genesove (2004) an analysis of industries where the product market is local (radio, newspapers, and hospital care are all locally produced and consumed) and the product is differentiated. Like these authors, and earlier work, we use the assumption that firms are symmetric, so that post-entry profits depend only on the number of firms in the market and on market level characteristics. To fully relax this assumption we would need to allow hospitals to choose their characteristics. While it is possible to use the methods pioneered by Mazzeo (2002) to model entry into differentiated products markets, these methods require a discrete measure of differentiation (e.g. discretely measured motel quality, as in Mazzeo). Hospitals are differentiated in multiple and complex ways, thus this industry does not lend itself to the use of these methods. An alternative would be fully to model demand, including pricing and characteristic choice. This would be contrary to the goal of our paper, however, which is to see how much we can learn about competition using a simple model which has relatively minimal data requirements. We conduct some auxiliary analyses to examine our assumptions and discuss in detail the implications of product differentiation for the interpretation of our results in Section 5 .

We lay out the model and econometrics in Section 2. Section 3 contains a description of the data. The empirical results are presented in Section 4. Section 5 contains a discussion of the inferences that can be drawn from the results, and Section 6 contains the summary and conclusions.

\section{Model and Econometrics}

The model below is based on the entry model of Bresnahan and Reiss (1991). Their model uses the concept of entry thresholds — the market sizes necessary to support successive entrants to a market - to infer how the toughness of competition varies with market structure. We integrate an analysis of the quantity transacted in the market with their framework, permitting a sharper inference of the effects of structure on competition. 


\subsection{Demand and Costs}

For this analysis, we take the output of hospital production to be a single product which is the composite of the set of all hospital services. Since most hospitals sell a common bundle of services (e.g., most hospitals offer obstetrics, surgery, emergency care, etc.), this assumption does capture an important aspect of institutional reality. ${ }^{5}$ Further, because of the importance of joint costs in the hospital industry, it is not clear that it is possible to analyze entry for individual services in a meaningful way. ${ }^{6}$

Let market demand for hospital services be:

$$
Q=d(P, X) \cdot S(Y)
$$

Market demand is the product of per capita demand (the demand of a representative consumer, $d(\cdot))$ and the total market size, $S(Y)$. Per capita demand is affected by price, $P$ and exogenous demand shifters such as demographic factors and health insurance coverage, $X$. We presume that consumers, or health insurers acting as their agents, care about the price of hospital services. There is ample evidence on this point (Manning et al., 1987; Feldman and Dowd, 1986). Demographic factors (e.g., age) are known to affect the demand for hospital care, as is income. The market size, $S$, is an increasing function of population and other variables, $Y$.

For simplicity, we assume that hospital costs are characterized by a constant average variable cost, $A V C(W)$, and a fixed (or sunk) cost, $F(W)$ depending upon cost-shifters, $W .^{7}$

\footnotetext{
${ }^{5}$ The majority of buyers of hospital services are managed care insurance plans, which purchase a bundle of hospital services for their enrollees. This assumption is nearly universally used in economic and antitrust analyses of the hospital industry (see Dranove and White, 1994; Dranove and Satterthwaite, 2000; Gaynor and Vogt, 2000).

${ }^{6}$ For some work along these lines, however, see Dranove et al. (1992).

${ }^{7}$ The assumption of constant average variable costs is not restrictive. Inferences from this model regarding
} 


\subsection{Equilibrium}

Following BR, we assume a symmetric equilibrium in price is reached in each market. For a market with $N$ firms, we will denote the equilibrium value $P_{N}$. Price depends upon demand and cost conditions as well as the toughness of competition, represented here by $\theta_{N}:{ }^{8}$

$$
P_{N}=P\left(X, W, \theta_{N}\right)
$$

In most static oligopoly models, variables which shift up market demand or reduce the elasticity at least weakly raise prices, as do variables which shift up marginal costs. Thus, we expect $P_{N}$ to be rising in those elements of $X$ and $W$ which increase demand and costs, respectively. The equilibrium value of $P$ induces equilibrium values of quantity, fixed costs, and variable profits:

$$
\begin{aligned}
d_{N} & =d\left(P_{N}, X\right) \\
F_{N} & =F(W, N) \\
V_{N} & =P_{N}-A V C(W)
\end{aligned}
$$

Following Bresnahan and Reiss (1991), we also allow fixed costs to depend directly on $N$. Generally, this dependence can reflect the existence of a scarce resource like a desirable location or a pool of entrepreneurs with heterogeneous geographic preferences, so that the fixed costs of entry may be higher for later entrants. In the case of the hospital industry, we think the assumption that later entrants have higher fixed costs reflects a hospital's need to build a cadre of referring physicians. The first entrant need not expend many resources on

conduct are unchanged even with U-shaped average costs (see Bresnahan and Reiss, 1991, 1988).

${ }^{8}$ Tougher competition with more competitors is a robust prediction of theoretical oligopoly models (Sutton, 1991; Bresnahan and Reiss, 1991). 
this task, as it is the only hospital to which physicians can refer. Later entrants anticipate expending resources to convince referring physicians to affiliate with them rather than with a competitor.

\subsection{Entry}

A hospital will enter a local market if it can earn non-negative profits. The Nth firm in a market earns profits equal to:

$$
\Pi_{N}=\left(P_{N}-A V C_{N}\right) \frac{S}{N} d_{N}-F_{N}
$$

The minimum market size necessary to support $N$ firms in the market, $S_{N}$, is derived by solving the zero-profit condition $\left(\Pi\left(S_{N}\right)=0\right)$. The per-firm minimum market size is:

$$
s_{N}=\frac{S_{N}}{N}=\frac{F_{N}}{\left(P_{N}-A V C_{N}\right) d_{N}}
$$

The per-firm entry threshold for $N$ firms, $s_{N}$, is the ratio of equilibrium fixed costs to the product of equilibrium variable profits and equilibrium per-capita demand. Following Bresnahan and Reiss, we examine ratios of entry thresholds to measure the rate at which variable profits fall with entry.

$$
\frac{s_{N+1}}{s_{N}}=\frac{F_{N+1}}{F_{N}} \frac{\left(P_{N}-A V C_{N}\right)}{\left(P_{N+1}-A V C_{N+1}\right)} \frac{d_{N}}{d_{N+1}}
$$

The entry threshold ratio, $s_{N+1} / s_{N}$, measures the product of two things: the change in fixed costs as $N$ increases and the change in per-capita variable profits as $N$ increases. The change in variable profits may be further decomposed into the change in per-capita quantity transacted and average variable profit. If competition is becoming tougher with entry, $\frac{d_{N+1}}{d_{N}}$ should be greater than one and $\frac{P_{N+1}-A V C_{N+1}}{P_{N}-A V C_{N}}$ less than one.

Ignoring for the moment the potential for changing fixed costs, a threshold ratio of 
one represents an unchanging level of competition, while a threshold ratio greater than one represents an increase in the toughness of competition. Bresnahan and Reiss (1991) interpret

a ratio $s_{N+1} / s_{N} \searrow 1$ as $N \rightarrow \infty$ as most naturally reflecting a market converging to the (unchanging) competitive equilibrium as the number of firms increases.

As equation 8 makes clear, the entry threshold ratios alone cannot separately identify the effect of entry on the toughness of price competition and the effect of entry on fixed costs. Our addition to the Bresnahan and Reiss (1991) framework is the use of information on quantity transacted separately to identify the quantity effect, $d_{N+1} / d_{N}$.

\subsection{Econometrics}

We observe the number of firms $(N)$ and quantity $(Q)$ for each market, so we seek equations for both $N$ and $Q$ from our theory. The model thus consists of the following two equations:

$$
\begin{aligned}
\Pi_{N} & =\frac{1}{N} S d_{N} V_{N}-F_{N} \\
Q_{N} & =S d_{N}
\end{aligned}
$$

Recall, however, that market size, $S$, is a function of population, $Y$. Per-capita demand, $d_{N}$, and variable profits, $V_{N}$, are functions of equilibrium price, $P_{N}$. Equilibrium price is a function of demand shifters, $X$, cost shifters, $W$, and the toughness of competition, $\theta_{N}$. However, we do not observe $P$ or $\theta$. We therefore express $d_{N}, V_{N}$, and $F_{N}$ as reduced form functions of the observables $X$ and $W$. We capture $\theta_{N}$, how the toughness of competition changes with the number of firms, flexibly and non-parametrically via a set of indicators of the number of firms in the market.

We specify market size, $S$, per-capita quantity, $d_{N}$, average variable profit, $V_{N}$, and fixed costs of entry, $F_{N}$, as: 


$$
\begin{aligned}
S & =\exp \left(Y \lambda+\epsilon_{S}\right) \\
d_{N} & =\exp \left(X \delta_{X}+W \delta_{W}+\delta_{N}+\epsilon_{d}\right) \\
V_{N} & =\exp \left(X \alpha_{X}+W \alpha_{W}-\alpha_{N}+\epsilon_{V}\right) \\
F_{N} & =\exp \left(W \gamma_{W}+\gamma_{N}+\epsilon_{F}\right)
\end{aligned}
$$

The parameters $\delta_{N}, \alpha_{N}$, and $\gamma_{N}$ are coefficients on dummy variables for market structure. They capture differences in per-capita quantity, average variable profit, and fixed costs among markets with one firm and markets with $N$ firms. For example, a positive value for $\gamma_{2}$ indicates that the fixed cost of entry for the second firm is greater than the fixed cost of entry for the first. A value of $\gamma_{3}>\gamma_{2}$ similarly indicates that the fixed cost of entry for the third firm is greater than the fixed cost of entry for the second, and so on. Similarly, positive and increasing (in $N)$ values of $\delta_{N}\left(\delta_{2}, \delta_{3}, \ldots\right)$ indicate per-capita quantity increasing with entry, and positive and increasing values of $\alpha_{N}\left(\alpha_{2}, \alpha_{3}, \ldots\right)$ indicate average variable profits falling with entry.

Note that Bresnahan and Reiss (1991) use a different specification for $S, d$, and $V$. They specify $S$ and $d \cdot V$ as linear functions of covariates, $S=Y \lambda$ and $d \cdot V=X \alpha_{X}+W \alpha_{W}$. We favor our logarithmic specification since it facilitates a clear discussion of identification (see the next section, 2.4.1).9

By substituting equations 11 through 14 into equation 9, we see that the entry equation becomes:

\footnotetext{
${ }^{9}$ As a check we also estimated a linear version of the model. The results were very similar. We do not report them here, but they are available on request.
} 


$$
\Pi_{N}=\exp \left(\begin{array}{c}
Y \lambda+X\left(\delta_{X}+\alpha_{X}\right)+W\left(\delta_{W}+\alpha_{W}\right) \\
+\delta_{N}-\alpha_{N}-\ln N+\epsilon_{S}+\epsilon_{d}+\epsilon_{V}
\end{array}\right)-\exp \left(W \gamma_{W}+\gamma_{N}+\epsilon_{F}\right)
$$

We can see that $\Pi_{N}>0$ as:

$$
\exp \left(\begin{array}{c}
Y \lambda+X\left(\delta_{X}+\alpha_{X}\right)+W\left(\delta_{W}+\alpha_{W}\right) \\
+\delta_{N}-\alpha_{N}-\ln N+\epsilon_{S}+\epsilon_{d}+\epsilon_{V}
\end{array}\right)>\exp \left(W \gamma_{W}+\gamma_{N}+\epsilon_{F}\right)
$$

i.e., as

$$
\begin{aligned}
& Y \lambda+X\left(\delta_{X}+\alpha_{X}\right)+W\left(\delta_{W}+\alpha_{W}-\gamma_{W}\right) \\
& +\delta_{N}-\alpha_{N}-\gamma_{N}-\ln N+\epsilon_{S}+\epsilon_{d}+\epsilon_{V}-\epsilon_{F}>0
\end{aligned}
$$

Denote $\mu_{N}=\alpha_{N}+\gamma_{N}+\ln N-\delta_{N}$ and $\mu_{X}=\delta_{X}+\alpha_{X}$, with $\mu_{W}$ similarly defined and also denoting $\epsilon_{\Pi}$ as the sum of the error terms above. Employing the fact that the number of firms in the market will be $\max \left\{N: \Pi_{N}>0\right\}$, we see that:

$$
N=\left\{\begin{array}{rlr}
0 & \text { if } & Y \lambda+X \mu_{X}+W \mu_{W}+\epsilon_{\Pi}<\mu_{1} \\
1 & \text { if } & \mu_{1}<Y \lambda+X \mu_{X}+W \mu_{W}+\epsilon_{\Pi}<\mu_{2} \\
2 & \text { if } & \mu_{2}<Y \lambda+X \mu_{X}+W \mu_{W}+\epsilon_{\Pi}<\mu_{3} \\
3 & \text { if } & \mu_{3}<Y \lambda+X \mu_{X}+W \mu_{W}+\epsilon_{\Pi}<\mu_{4} \\
4+ & \text { if } & \mu_{4}<Y \lambda+X \mu_{X}+W \mu_{W}+\epsilon_{\Pi}
\end{array}\right.
$$

Note that if $\epsilon_{\Pi}$ has a normal distribution, then the entry model is a standard ordered probit with threshold values given by the $\mu_{N}$.

Substituting (11) and (12) into (10), we obtain the quantity equation: 


$$
\ln Q_{N}=Y \lambda+X \delta_{X}+W \delta_{W}+\delta_{N}+\epsilon_{S}+\epsilon_{d}
$$

The relevant quantity for purposes of the entry equation is some measure of expected long run quantity. However, we observe quantity at a single point in time for each market, thus this likely measures long run quantity with error. We therefore add a term for measurement error, defining $\epsilon_{Q}=\epsilon_{S}+\epsilon_{d}+\epsilon$, yielding:

$$
\ln Q_{N}=Y \lambda+X \delta_{X}+W \delta_{W}+\delta_{N}+\epsilon_{Q}
$$

The quantity equation cannot be estimated by OLS for two reasons. First, $Q$ is unobservable for $N=0$. This would not be a problem if the selection of markets for which $N=0$ were random, but it is not. Looking at the entry equation, whether $N=0$ is determined in part by $\epsilon_{S}$ and $\epsilon_{d}$. Hence there would be selection bias in estimating equation 18 by OLS. Second, and for similar reasons, the number of firms in the market, $N$, is endogenous to $\epsilon_{S}$ and $\epsilon_{d}$. This means that the market structure dummies, of which the $\delta_{N}$ are the coefficients, are endogenous.

\subsubsection{Identification}

Observe that from the entry equation alone, (15), it is possible to identify only $\left(\delta_{X}+\alpha_{X}\right)$, $\left(\delta_{W}+\alpha_{W}-\gamma_{W}\right)$, and $\left(\delta_{N}-\alpha_{N}-\gamma_{N}\right)$. Changes in $\left(\delta_{N}-\alpha_{N}-\gamma_{N}\right)$ with $N$ control the behavior of the population threshold ratios as $N$ increases.

If market population is an element of $Y$, and it is entered in logs with a coefficient of $\lambda_{\text {pop }}$, then it is easy to see that the per-firm population threshold ratio is: 


$$
\begin{aligned}
\frac{s_{N+1}}{s_{N}} & =\exp \left(\frac{\delta_{N}-\alpha_{N}-\gamma_{N}-\delta_{N+1}+\alpha_{N+1}+\gamma_{N+1}}{\lambda_{\text {pop }}}\right) \\
& =\exp \left(\frac{\gamma_{N+1}-\gamma_{N}}{\lambda_{\text {pop }}}\right) \exp \left(\frac{\alpha_{N+1}-\alpha_{N}}{\lambda_{\text {pop }}}\right) \exp \left(\frac{\delta_{N}-\delta_{N+1}}{\lambda_{\text {pop }}}\right)
\end{aligned}
$$

The expression in equation 19 demonstrates that the per-firm population thresholds depend on how $\left(\delta_{N}-\alpha_{N}-\gamma_{N}\right)$ changes with $N$. Equation 20 echos the expression in equation 8 , showing that changes in fixed costs, variable profits, and per-capita demand are not identified separately in the entry equation alone. In Bresnahan and Reiss (1991), $\gamma_{N}$ and $\delta_{N}-\alpha_{N}$ are separately identified only because of the imposition of the linear functional form. ${ }^{10}$ That is, any pattern of threshold ratios is consistent with any pattern of $\delta_{N}$ and $d_{N}$, since $\gamma_{N}$ can be adjusted to make any pattern of threshold ratios consistent with any pattern of $\delta_{N}$ and $\alpha_{N}$.

The additional identification achieved by including a quantity equation is revealed by examining equations 15 and 18. From the quantity equation we are able to identify $\delta_{N}, \delta_{X}$, and $\delta_{W}$. Therefore, from the quantity and entry equations, we are able separately to identify $\delta_{N}, \delta_{X}, \delta_{W},\left(\alpha_{N}+\gamma_{N}\right),\left(\alpha_{W}+\gamma_{W}\right)$, and $\alpha_{X}$

By using outside information, we may be able to go further in identifying the parameters of this model. Suppose we know the market elasticity of demand, $\eta_{d}$, in the relevant industry and we know the average profit margin, $\frac{P_{N}-A V C_{N}}{P_{N}}$, for some $N$. Then, we know that the percent price decline due to the entry of the $(N+1)^{\text {th }}$ firm is $\frac{\delta_{N+1}-\delta_{N}}{\eta_{d}}$. The percent change in $P_{N}-A V C_{N}$ due to a 1 percent change in $P_{N}$ is:

$$
\frac{\partial\left(P_{N}-A V C_{N}\right)}{\partial P_{N}} \frac{P_{N}}{P_{N}-A V C_{N}}=1 \cdot \frac{P_{N}}{P_{N}-A V C_{N}}=\frac{1}{\frac{P_{N}-A V C_{N}}{P_{N}}}
$$

\footnotetext{
${ }^{10}$ We claim no originality for this insight, as a close reading of Bresnahan and Reiss (1991) reveals that those authors are aware of as much.
} 
Thus, we know $\alpha_{N+1}-\alpha_{N}$, the decline in average variable profit from the entry of the $(N+1)^{\text {th }}$ firm. It is $\frac{\delta_{N+1}-\delta_{N}}{\eta_{d}} \frac{P_{N}}{P_{N}-A V C_{N}}$. Given the normalizations $\delta_{1}=\alpha_{1}=0$, this gives us all the $\alpha_{N}$ and thus all the $\gamma_{N}{ }^{11}$

\subsubsection{Distributional Assumptions and Likelihood}

The two equations we wish to estimate are an ordered-probit entry equation and a linked demand equation which has both selection bias and endogeneity of the market structure dummies:

$$
\begin{aligned}
& Y \lambda+X\left(\delta_{X}+\alpha_{X}\right)+W\left(\delta_{W}+\alpha_{W}-\gamma_{W}\right) \\
& +\delta_{N}-\alpha_{N}-\gamma_{N}-\ln N+\epsilon_{\Pi}>0 \\
& \ln Q_{N}=Y \lambda+X \delta_{X}+W \delta_{W}+\delta_{N}+\epsilon_{Q}
\end{aligned}
$$

The error terms in these two equations are sure to be correlated because they have in common the terms $\epsilon_{S}$ and $\epsilon_{d}$. They are not perfectly correlated, however, because $\epsilon_{Q}$ contains the measurement error term $\epsilon$ which is absent from $\epsilon_{\Pi}$, and because $\epsilon_{\Pi}$ contains the cost and average variable profit error terms, $\epsilon_{F}$ and $\epsilon_{V}$, which do not appear in the demand equation. In addition, there is reason to believe that $\epsilon_{d}$ (in both equations) and $\epsilon_{V}$ (in the entry equation only) are negatively correlated. The toughness of price competition, $\theta_{N}$, may vary across markets. In markets with tough price competition, price will be lower, inducing both higher quantity and lower average variable profits, hence a negative correlation between $\epsilon_{d}$ and $\epsilon_{V}$.

The nature of the endogeneity and selection in the quantity equation is now clear. In

\footnotetext{
${ }^{11}$ Obviously, this reasoning depends in an important way on three assumptions: that there are no scale economies, that the only demand-relevant variable which changes upon entry is price, and that average variable costs do not change with entry, as, e.g. a valuable local input's price is bid up.
} 
markets which have high demand unobservables, $\epsilon_{S}$ and $\epsilon_{d}$, observed quantity is higher than it would otherwise be from the direct effect of the demand errors on the quantity equation, and the number of firms is also higher than it would otherwise be, via the effect of the demand errors on the entry equation. Since this correlation does not come from the competitive effect we are trying to measure with $\delta_{N}$, it will bias the estimation of $\delta_{N}$, making the effect of competition on quantity look larger than it is in fact. Conversely, the endogeneity coming from $\theta_{N}$ will tend to understate the competitive effects. High quantity will correlate with low $N$ because markets with tough competition will have fewer firms and lower prices. Which of these effects dominates is an empirical matter.

This leads to a slightly non-standard selection model. The entry equation is the selection equation. It selects whether or not we see $Q$ (we do not see $Q$ if $N=0$ ). It then selects which number of firms we will see in each market and therefore which $\delta_{N}$ we will be estimating in the quantity equation for each market. Selection models like this one may be consistently estimated via maximum likelihood given a distributional assumption on the errors.

To reflect the correlation between the error terms in the two equations, we use a variance components model:

$$
\begin{aligned}
& \epsilon_{\Pi}=\nu_{\Pi}+r \eta \\
& \epsilon_{Q}=\nu_{Q}+\eta
\end{aligned}
$$

We assume that $\nu_{\Pi}$ and $\nu_{Q}$ are independent normals with mean zero and variances $\sigma_{\nu_{\Pi}}^{2}$ and $\sigma_{\nu_{Q}}^{2}$, respectively. ${ }^{12}$ We also assume that the random variable $\eta$ is independent of $\nu_{\Pi}$ and $\nu_{Q}$ and that it has a mean of zero.

The dependence in the errors between the two is modeled via the common random vari-

\footnotetext{
${ }^{12}$ Since the entry equation is an ordered probit, one might think that the variance of $\nu_{\Pi}$ is not identified. In our model, however, it is because $\lambda$ is identified from equation 18, so that no normalization is necessary in equation 15.
} 
able $\eta$ and the parameter $r$. If $r>0$, then the entry equation and quantity equation errors are positively correlated and if $r<0$, then they are negatively correlated. Since the percapita demand and the market size errors appear in both the entry and quantity equation with the same sign, we expect that $r>0$.

With some additional assumptions, we can sharpen the interpretive power of $r$. Assume that both $\epsilon_{S}$ and $\epsilon_{F}$ are independent of $\epsilon_{d}$ and $\epsilon_{V}$. In this case, $\eta$ is modeling the correlation between $\epsilon_{d}$ and $\epsilon_{d}+\epsilon_{V}$. Were $\epsilon_{V}$ and $\epsilon_{d}$ to be uncorrelated, we would see $r=1$. If, on the other hand, $\epsilon_{d}$ and $\epsilon_{V}$ were to be positively correlated, then we would see $r>1$, and if they are negatively correlated, $r<1$. Now, $\epsilon_{d}$ and $\epsilon_{V}$ would be positively correlated if variations in $\eta$ were picking up mostly variation in demand conditions with an unchanging toughness of price competition. High demand markets, holding all else constant, should have (at least weakly) higher average variable profits (holding constant the number of firms). On the other hand, $\epsilon_{d}$ and $\epsilon_{V}$ would be negatively correlated if variations in $\eta$ were picking up variations in the toughness of competition. In hard competition markets, quantity would be higher and average variable profits lower owing to the lower price. So, under these additional assumptions, we can interpret $r>1$ as indicating significant unobserved variation in demand and $r<1$ indicating significant unobserved variation in the hardness of price competition among markets. Of course, both things could be occurring, in which case comparing $r$ to one only tells us which effect is dominant.

Because $\nu_{Q}, \nu_{\Pi}$, and $\eta$ are mutually independent, $\epsilon_{\Pi}$ and $\epsilon_{Q}$ are independent once we condition on $\eta$. Consider now the contribution (conditional on $\eta$ ) to the likelihood function of a market with $N=0$ : 


$$
\begin{aligned}
& P\{N=0 \mid \eta\}=P\left\{Y \lambda+X \mu_{X}+W \mu_{W}+\epsilon_{\Pi}<\mu_{1} \mid \eta\right\} \\
& P\{N=0 \mid \eta\}=P\left\{Y \lambda+X \mu_{X}+W \mu_{W}+\nu_{\Pi}+r \eta<\mu_{1} \mid \eta\right\} \\
& P\{N=0 \mid \eta\}=\Phi\left(\mu_{1}-Y \lambda-X \mu_{X}-W \mu_{W}-r \eta\right)
\end{aligned}
$$

The contribution (conditional on $\eta$ ) to the likelihood function of a market with $N=n$ is:

$$
\begin{aligned}
& P\{N=n \mid \eta\} f(\ln Q \mid \eta)=P\left\{\mu_{n}<Y \lambda+X \mu_{X}+W \mu_{W}+\nu_{\Pi}+r \eta<\mu_{n+1} \mid \eta\right\} f(\ln Q \mid \eta) \\
& =\left(\begin{array}{c}
\Phi\left(\mu_{n+1}-Y \lambda-X \mu_{X}-W \mu_{W}-r \eta\right) \\
-\Phi\left(\mu_{n}-Y \lambda-X \mu_{X}-W \mu_{W}-r \eta\right)
\end{array}\right) \frac{1}{\sigma_{\nu_{Q}}} \phi\left(\frac{\ln Q-Y \lambda-X \delta_{X}-W \delta_{W}-\delta_{N}-\eta}{\sigma_{\nu_{Q}}}\right)
\end{aligned}
$$

Finally, the contribution (conditional on $\eta$ ) to the likelihood function of a market with $N=\bar{n}$, where $\bar{n}$ is the "top" category in the ordered probit, is:

$$
\begin{aligned}
& P\{N=\bar{n} \mid \eta\} f(\ln Q \mid \eta)=P\left\{\mu_{\bar{n}}<Y \lambda+X \mu_{X}+W \mu_{W}+\nu_{\Pi}+r \eta \mid \eta\right\} f(\ln Q \mid \eta) \\
& \quad=\left(1-\Phi\left(\mu_{\bar{n}}-Y \lambda-X \mu_{X}-W \mu_{W}-r \eta\right)\right) \frac{1}{\sigma_{\nu_{Q}}} \phi\left(\frac{\ln Q-Y \lambda-X \delta_{X}-W \delta_{W}-\delta_{N}-\eta}{\sigma_{\nu_{Q}}}\right)
\end{aligned}
$$

Now let us turn to $\eta$. Let $\eta$ be distributed with a distribution function $F(\eta ; \beta)$ which depends on parameters $\beta$. Then the contribution of an observation with $N=n$ where $n$ is neither zero nor the top category would be: 


$$
\begin{aligned}
& \int_{\eta} P\{N=n \mid \eta\} f(\ln Q \mid \eta) d F(\eta ; \beta)= \\
& \quad\left(\begin{array}{c}
\Phi\left(\mu_{n+1}-Y \lambda-X \mu_{X}-W \mu_{W}-r \eta\right) \\
-\Phi\left(\mu_{n}-Y \lambda-X \mu_{X}-W \mu_{W}-r \eta\right)
\end{array}\right) \frac{1}{\sigma_{\nu_{Q}}} \phi\left(\frac{\ln Q-Y \lambda-X \delta_{X}-W \delta_{W}-\delta_{N}-\eta}{\sigma_{\nu_{Q}}}\right) d F(\eta ; \beta)
\end{aligned}
$$

To arrive at the unconditional contribution to the likelihood function, we must integrate over $\eta$. Rather than assuming a particular functional form for the distribution of $\eta$, we choose to approximate this distribution using a discrete factor approximation (Heckman and Singer, 1984; Mroz and Guilkey, 1992). This entails using a multinomial distribution for $\eta$ with $K$ points of support:

$$
\eta=\left\{\begin{array}{ccc}
\beta_{1} & \text { with probability } & p_{1} \\
\beta_{2} & \text { with probability } & p_{2} \\
\beta_{3} & \text { with probability } & p_{3} \\
\vdots & \vdots & \vdots \\
\beta_{K} & \text { with probability } & p_{K}
\end{array}\right.
$$

The use of this distribution with $K$ points of support introduces $2 K$ additional parameters, the $K \beta$ s and the $K p$ s. However, the requirement that the probabilities sum to one and the requirement that the expected value of $\eta$ be zero reduces the number of parameters to $2(K-1)$.

At last, the unconditional contribution to the likelihood function of an observation with $N=n$ where $n$ is neither zero nor the top category is: 


$$
\begin{aligned}
& \int P\{N=n \mid \eta\} f(\ln Q \mid \eta) d F(\eta ; \beta)= \\
& \quad \sum_{k=1}^{K} p_{k}\left(\begin{array}{c}
\Phi\left(\mu_{n+1}-Y \lambda-X \mu_{X}-W \mu_{W}-r \beta_{k}\right) \\
-\Phi\left(\mu_{n}-Y \lambda-X \mu_{X}-W \mu_{W}-r \beta_{k}\right)
\end{array}\right) \frac{1}{\sigma_{\nu_{Q}}} \phi\left(\frac{\ln Q-Y \lambda-X \delta_{X}-W \delta_{W}-\delta_{N}-\beta_{k}}{\sigma_{\nu_{Q}}}\right)
\end{aligned}
$$

The contributions for observations with $N=0$ and with $N$ equal to the top category in the ordered probit may be derived similarly. It is this likelihood function which we take to the data. It remains to choose a $K$, and we follow the prior literature in that we increase $K$ until the likelihood function no longer rises appreciably with further increases in $K$. In our case, raising $K$ from six to seven resulted in the likelihood function rising by approximately 0.05 , so we set $K$ equal to seven.

Both principled and pragmatic reasons recommend the discrete factor approximation as a way of introducing correlation between two equations in an econometric model. Because the discrete factor's distribution is parameterized in a way which is essentially non-parametric, it can reduce the bias which would otherwise result from assuming normal errors where the errors are not in fact normal. Monte Carlo simulations using discrete factor approximations in selection models and simultaneous equations models have shown that discrete factor approximations perform approximately as well as Normal maximum likelihood when the equation errors are truly normal, and that discrete factor approximations provide good estimators of underlying structural parameters in the presence of non-normality in the error terms (Mroz and Guilkey, 1992; Mroz, 1999).

Pragmatically, the distributions of the error terms of each equation of the model conditional upon the discrete factor, $\eta$, are normal and independent of each other. This makes both the analytical derivation of the likelihood function and the programming of the likelihood function easy. It is simple to use off-the-shelf statistical software to estimate these 
models. $^{13}$

\section{Data}

\subsection{Market Definition}

The unit of analysis is a market for hospital services. Markets for hospital services are local, owing to the nature of the service (Frech, 1987). There is no single, agreed upon method for empirical market definition, although it is clear that the markets should be "self-contained" in the sense that there is not relevant competition from outside the market. We thus follow Bresnahan and Reiss by focusing on geographically isolated markets as a way of minimizing the possibility of competition coming from outside the defined market.

With that in mind, we define our markets using the following selection criteria. First, we identified all cities and census designated places (CDPs) in the United States with populations of at least 5,000, using the 1990 Census. Each of these we designate a potential market. Second, to reduce the possibility of market overlap, we eliminate potential markets that are within 50 miles of a city with a population of at least 100,000, or within 15 miles of another potential market. Third, we eliminate all potential markets in which a hospital was located outside of the city but within 15 miles. Finally, markets that were on Indian reservations or located in Alaska or Hawaii were excluded from the analysis. Applying these criteria, we identify 613 markets with 490 hospitals.

These markets contain 12.26 million people collectively, about 4.4 percent of the U.S. population. The 490 hospitals represent about 9.1 percent of U.S. hospitals. In Table 1, we compare the size distribution of the hospitals in our sample to the overall distribution of US hospitals. As one might expect, given that our sample selection criteria exclude big cities, we under-sample large hospitals. Furthermore, given that ignore places with population smaller

\footnotetext{
${ }^{13}$ For example, both Stata and TSP easily implement the model we consider in this paper, and we use TSP for our estimates.
} 
than 5,000, we also under-sample the very smallest hospitals. Markets like ours have been disproportionately represented in antitrust cases. Three out of the 11 hospital merger cases (27.3\%) brought by the U.S. antitrust enforcement agencies in the last twenty years were against hospitals located in markets contained in our sample. A number of the other 11 cases were also in similar markets with a very small number of hospitals, although they were not in our analysis sample. Figure 1 contains a map illustrating the locations of these markets.

As a check of our market definition, we include in our regressions the natural log of the distance from a hospital market to the nearest city with a population of at least 100,000, the natural $\log$ of the distance from a hospital market to the nearest city with a population of at least 5,000, and the proportion of commuters traveling at least 45 minutes to work. These variables should pick up "leakages" to or from nearby locations.

We also note that geographic differentiation is one of the most important aspects of product differentiation in this industry. A large literature (see Capps et al., 2003; Gaynor and Vogt, 2003, 2000, and references therein) finds that geographic differentiation is extremely important in hospital demand, and that consumers strongly prefer hospitals close to their homes. Our method of market definition results in very small markets, thereby minimizing the extent of geographic differentiation in the markets we analyze.

\subsection{Data and Measures}

\subsubsection{Sources}

We use data from a variety of sources, including the American Hospital Association (American Hospital Association, 1990), the 1990 U.S. Census, the Area Resource File (Bureau of Health Professions, 1996), the InterStudy National HMO Census (InterStudy, 1990), and the Missouri Certificate of Need Program (Piper, 1998). 


\subsubsection{The Number of Firms, $\mathrm{N}$}

The number of firms is defined as the total number of short-term general hospitals with 50 or more beds in a local market. We eliminate any hospitals with fewer than 50 beds on the grounds that they are not effectively full service hospitals. Military hospitals are also excluded, since they do not serve the general public. We identified hospitals and their location from the American Hospital Association (American Hospital Association, 1990). Table 2 contains the distribution of hospital market structures and their average populations in our sample.

\subsubsection{Quantity, Q}

The measure we use for quantity is total adjusted admissions in the market. ${ }^{14}$ These data come from the American Hospital Association, which collects this information from all hospitals in the U.S. on an annual basis (American Hospital Association, 1990). Adjusted admissions allow for the fact that hospitals provide both inpatient and outpatient care by creating a weighted average of the two, where the weight for inpatient admissions is 1 and for outpatient visits is the ratio of outpatient charges per visit to inpatient charges per admission. There are other commonly used measures of hospital quantity, such as inpatient admissions alone, inpatient hospital days, or hospital beds. We examined the correlations between all pairs of these measures. Each correlation was greater than 0.9.

\subsubsection{Market Size, S(Y)}

Population, $Y$, is the key determinant of market size, $S$. We use data from the 1990 Census on the population of the places that are markets in our sample. Population means by market structure are contained in Table 2. The mean population size for the entire sample is 19,102.

Using population of the place may not accurately represent the total population of the

\footnotetext{
${ }^{14}$ For short-term, general, non-military hospitals.
} 
market if individuals living outside the place travel there to obtain hospital services. To control for potential inflows, we include a measure of the market fringe population, defined as the population located outside the place, but within 15 miles. In contrast, some residents of the place may choose to travel outside of the local market to obtain hospital services. We proxy for this potential outflow by including the proportion of residents who commute more than 45 minutes to work. Assuming this measure is correlated with residents' willingness to travel to obtain care elsewhere, this should be associated with a decrease in the demand for hospital services in the market.

Last, we include an indicator variable for whether the market has a military base. Since military personnel may obtain health care from military facilities, demand may be lower in an area with a military base than in an otherwise similar area without one. ${ }^{15}$

\subsubsection{Demand Shifters, X}

Referring back to equations (12) and (13), per capita demand, $d_{N}$, and variable profits, $V_{N}$, are determined in part by exogenous demand shifters, $X$, such as demographic factors, income, and insurance. Data for these variables come from the 1990 Area Resource File (Bureau of Health Professions, 1996). The major demographic factor is age. The proportion of the population 65 years of age and older in the market should be positively associated with demand for hospital services. Illness increases with age, and thus demand for health care. This population is also eligible to receive Medicare, thereby increasing insurance coverage and hence demand. The measure of income we use is per capita income for the place's population. This may not only capture the direct effects of income on demand, but the extent of health insurance coverage in the population, since insurance coverage is positively associated with income.

We also include the number of health maintenance organizations (HMOs) as a factor

\footnotetext{
${ }^{15}$ Recall that military hospitals are excluded from the count of hospitals and from the measure of quantity.
} 
affecting demand. HMOs have two effects on demand. First, HMOs attempt directly to control the amount and type of health care use, specifically focusing on keeping patients out of the hospital, directly reducing demand for hospital services. Second, HMOs often contract with a subset of hospitals in a market to provide services for their enrolled population, making choices based in large part on price. This leads to hospitals facing more elastic demand for their services. We use the number of HMOs operating in the county of the market in 1990 (InterStudy, 1990). ${ }^{16}$ The number of HMOs operating in a market is arguably endogenous, but, in our application this variable is never significant, and excluding it does not affect our results.

\subsubsection{Cost Shifters, W}

Both variable profits (13) and fixed costs (14) are affected by exogenous cost shifters, $W$. Hospitals utilize various labor inputs in the provision of acute care. We use the Centers for Medicare and Medicaid Services' (CMS) hospital wage index as a measure of hospitals' labor costs. ${ }^{17}$ We also include median gross rent, defined to be the median rent paid by renteroccupied housing units in the market, and CMS's area construction cost index to control for differences across markets in facility or building costs. ${ }^{18}$ In addition to labor and facility costs, hospitals may incur costs associated with regulatory compliance. The National Health Planning and Resources Development Act of 1974 mandated that states establish "certificate of need" (CON) programs (Joskow, 1980). These programs require hospitals and other health care providers to obtain formal approval before making large capital investments, which include the construction of new hospitals and expansion of existing facilities (Phelps, 1997). Many but not all states have subsequently allowed their CON laws to lapse. We interpret

\footnotetext{
${ }^{16}$ We thank Doug Wholey for providing us with these data.

${ }^{17}$ This wage index was developed for the purposes of Medicare hospital payment. CMS is the U.S. government agency which runs Medicare.

${ }^{18}$ The CMS construction cost index was also developed for the purposes of Medicare hospital payment.
} 
this regulation as a fixed cost that hospitals incur when choosing to enter a market. Our binary measure for the presence of a certificate of need program is CON.

Table 3 contains variable definitions and descriptive statistics.

\section{Results}

We begin by reporting results for the entry and quantity equations estimated separately as single equations (Table 4). These estimates are useful for comparing with the main results obtained by estimating the entry and quantity equations jointly. Estimating the entry equation as a single equation also corresponds to the method employed by Bresnahan and Reiss, allowing us to compare the joint estimation results with those obtained with their method.

Table 4 (second column) contains the estimates from the single equation entry model. To generate these estimates, we regressed the number of firms in a market on all of our market size, demand, and cost shifters using ordered probit. This technique produces consistent estimators of $\delta+\alpha-\gamma$ and the threshold ratios as long as $\epsilon_{\Pi}$ is normal, since equation 16 describes an ordered probit model. This ordered probit model differs from Bresnahan and Reiss (1991) only in that we use a log-log rather than linear functional form for the components of the profit function. As is readily apparent, almost all of the coefficients in this table have the "right" sign. The demand and market size shifters raise the expected number of firms in the market, and the cost shifters reduce it. The coefficients on construction cost index and distance to a big city have statistically insignificant coefficients of the "wrong" sign, and the coefficient on military base has a large, significant coefficient of the wrong sign. We discuss the threshold ratios for this model below.

In the third column of Table 4 we report parameter estimates of the quantity equation derived by estimating equation 18 by OLS using only the markets in which at least one hospital is present. These estimates were generated by regressing the natural log of quan- 
tity in each market on the market size shifters, demand shifters, and variable cost shifters, along with a set of market structure dummies. As indicated previously, these estimates are inconsistent both because there is selection bias caused by the unobservability of $\ln Q$ when no hospitals are present and because of the endogeneity of the market structure dummies. We can correct the first of these problems by estimating a Heckman sample selection model. Maximum likelihood estimates from such a model are reported in the fourth column of the table. The first stage regression of the sample selection model included all the variables in the table plus the certificate of need variable and the construction cost index. ${ }^{19}$

For both of these models, many of the point estimates are again reasonable. The market size and demand shifters largely increase the market quantity transacted and the cost shifters largely reduce it. The market structure dummies also have the expected pattern. As more hospitals enter, the quantity transacted in the market rises. Furthermore, the incremental rise in demand with entry decreases as more firms enter, consistent with competition becoming tougher but approaching the competitive level as $N$ increases. By the fourth firm, demand is no longer rising appreciably in entry, and in the OLS estimation it even seems to decline slightly (from 0.688 to 0.661 ). However, in both models the market structure dummies have an implausibly large effect on the quantity transacted. In the selection model, for example, a market with four firms has an expected demand $e^{0.661}=1.94$ times as large as the same market would have with a single firm. This is consistent with the market structure dummies being endogenous — markets with high unobserved demand will also have many firms because the high demand causes entry.

We now turn to the main results from our model. Table 5 contains the parameter estimates from the maximum likelihood estimation of equations 15 and 18 with the discrete factor approximation. ${ }^{20}$ The parameter estimates are organized according to whether the

\footnotetext{
${ }^{19}$ The first stage estimates are not reported here, but are available upon request.

${ }^{20}$ We also estimated the model suppressing the discrete factor approximation. Those estimates are reported in the column labeled "No DFA." We discuss those estimates later.
} 
variables enter the market size, per-capita demand, variable profits, or fixed cost branch of the entry model. ${ }^{21}$

The parameter estimates are largely reasonable. The coefficient on population in the market size branch of the model says that a $1 \%$ increase in market population raises the level of demand by $0.83 \%$. Similarly, an increase in fringe population of $1 \%$ raises quantity by $0.21 \%$. Thus, the effect of fringe population on demand is about $68 \%$ as large as is the effect of market population on demand. Military bases appear to have a small and insignificant effect in this model.

In the per-capita quantity branch of the model, we are estimating $\delta$, the effect of the various covariates on equilibrium quantity transacted in the market. The cost shifters, wages and rent, have the expected negative sign, although the parameters are imprecisely estimated. Similarly, the demand shifters, income, commuters, and percentage elderly affect per-capita quantity in the expected direction. The distance variables show some evidence that our market definition procedure was not completely successful in isolating truly selfcontained geographical markets. The coefficient on distance to a big city is very small. With respect to large cities, our markets seem far enough away that leakage is not an empirically important phenomenon. For small cities, this is less true. The coefficient on distance to a small city shows that a $1 \%$ decrease in the distance to a small city decreases local quantity by $0.22 \%$. Markets with small cities closer to them have lower demand.

The market structure dummies show that quantity increases substantially with the entry of the second firm, more modestly with the entry of the third firm and that it drops with the entry of the fourth firm. Expected demand with two firms is $e^{0.254}=1.29$ times as large as it is with one firm. Expected demand with three firms is $e^{0.415-0.254}=1.17$ times as large as with two firms, and quantity is $e^{0.297-0.415}=0.89$ times as large with four or more firms as with three. However, because we have only five markets with four or more firms and eight

\footnotetext{
${ }^{21}$ In performing this estimation, we expressed all of the right-hand-side variables in deviations from their means. This affects only the estimates of the intercept parameters in each equation.
} 
markets with three firms, the coefficients on the three and four firm market structures are imprecisely estimated. For example, $\delta_{3}$ and $\delta_{4}$ are not significantly different from one another at conventional significance levels $(\mathrm{t}-\mathrm{stat}=0.64)$, nor are $\delta_{2}$ and $\delta_{3}$ significantly different from one another at conventional significance levels ( $\mathrm{t}-\mathrm{stat}=1.25)$.

Recall that the coefficients in the average variable profits branch of the model, $\alpha$, are not separately identified from the coefficients in the fixed cost branch of the model, $\gamma$. Only $\alpha-\gamma$ is identified. However, for many of the variables we are interested in, identification can be achieved via parameter restrictions. The next section of Table 5 contains variables which are in $X$ but not $W$ : variables we are willing to assume shift demand but not cost. Thus, the coefficients in that part of the table estimate $\alpha_{X}$. None of these coefficients are significant at conventional levels, but, at point estimates, most of them have either no effect or an effect in the expected direction.

Similarly, an exclusion restriction allows us to identify the effects of certificate of need regulation and construction costs on fixed costs. To exclude these variables from $\alpha$, we assume that they affect neither demand nor variable costs, which seems reasonable. As in the variable profits branch of the model, these variables' coefficients are imprecisely estimated.

Two of our cost variables plausibly affect both fixed and variable costs, wages and rent; thus, we are able to identify only $\gamma-\alpha$. Since we expect increases in these variables to raise fixed costs and to lower variable profits (because they raise variable costs), we expect $\gamma-\alpha$ to be positive for both. As the results in the variable profits and fixed cost section of Table 5 show, these expectations are borne out. Wages have an almost unit elasticity on the ratio of variable profits to fixed costs and rent also has a positive if smaller and statistically insignificant estimated effect.

Finally, the effects of market structure on variable profits and fixed costs are not identified separately. We can see only $\gamma_{N}-\alpha_{N}$, the percent increase in fixed costs plus the percent decline in variable profit relative to monopoly for each market structure. The results in the entry effects subsection of Table 5 show that the entry of the second firm has a strong negative 
effect on average variable profits net of fixed costs. The effects of subsequent entrants are smaller, and, again, the point estimates indicate that the entry of the fourth firm actually decreases fixed costs net of average variable profits. However, as in the per-capita quantity branch of the model, the difference in the effects of the third and fourth firms is neither large nor significant at conventional levels $(\mathrm{t}$-stat $=0.51)$. Here, however, the t-stat for the effect of the third firm is significant at conventional levels (t-stat=3.14).

The estimates of the parameters of the discrete factor approximation appear next in Table 5. Since our discrete factor approximation had seven points of support, we have fourteen parameters: the seven values $\eta$ can take on, the $\beta \mathrm{s}$, and the seven probabilities associated with these seven values, the $p$ s. Of course, in a sense there are only really twelve parameters, as the probabilities must sum to one and, because there are constants in all the relevant econometric equations, the expectation of $\eta$ must be restricted to zero.

The fourteen parameter estimates along with their associated standard errors are presented in the section entitled "Error distributions." It is clear that the distribution of $\eta$ is non-normal. There is a large probability mass near zero. The fifth and sixth points of support account for about $98 \%$ of the probability mass, and they are relatively close to zero, at -0.093 and 0.336 . The asymmetry in $\eta$ 's distribution is striking even looking only at these two "middle" points of support. If the distribution of $\eta$ were to be approximating a normal, we would expect to see the two middle points of support having roughly equal probability weight and lying roughly an equal distance from the origin. By contrast, the fifth point of support lies at -0.093 with a probability of 0.644 while the sixth lies at 0.336 (more than three times as far from the origin) with a probability of 0.336 (less than half the mass as on the fifth). None of the other points of support has even $1 \%$ probability on it. In addition to this, $\eta$ has a very long left tail, with its lowest point at -4.845 and its highest at 1.563 . Additionally, we calculated the skewness statistic for the distribution of $\eta$. It is -6.43 (and highly significant), cementing the case for non-normality.

In addition to being non-normal, $\eta$ is substantively relevant. Consider that the error 
term in the quantity equation is $\nu_{Q}+\eta$. The variance of $\nu_{Q}$ is estimated to be 0.236 while the variance of $\eta$ is estimated to be 0.241 . Thus, $\eta$ accounts for about half of the variance in the quantity equation (recall that we assume that $\nu_{Q}$ and $\eta$ are independent). The error term in the entry equation is $\nu_{\Pi}+r \eta$. The variance of $\nu_{\Pi}$ is estimated at 0.372 while the variance of $r \eta$ is estimated at 0.013 . So, $\eta$ accounts for a modest $3.4 \%$ of the variance in the entry equation. This sharp contrast is due to the small estimated value of $r$, at 0.23 .

Since we know that $\eta$ enters the quantity equation directly (i.e. with a coefficient of one), and since the log of quantity enters the entry equation linearly, the estimate of 0.23 for $r$ means that $\eta$ must enter either the average variable profit equation negatively or the fixed cost equation positively. ${ }^{22}$ Let's consider the former and think about what kind of unobserved heterogeneity $\eta$ represents. If it were to represent unobserved heterogeneity in demand alone, we should expect it to enter the average variable profit equation with the same sign it enters the demand equation - that is, high demand markets should also have high (or at least the same) average variable profits. In contrast, if $\eta$ represents unobserved heterogeneity in the toughness of price competition, it should enter average variable profits and quantity with opposite signs: markets with tougher competition should have higher quantity and lower average variable profits. Obviously, both types of heterogeneity could be operating. Since $\eta$ seems to be entering average variable profits with a negative sign (since $r<1$ ), the latter effect seems to dominate here. That is, it appears that there is important heterogeneity in the toughness of price competition among markets.

The discrete factor approximation is also of substantial econometric significance. By adding the discrete factor approximation and the associated thirteen parameters (twelve for the discrete factor approximation and one for $r$ ), the log likelihood in the model rises from about -589 to -467 . There is also a large difference in the estimates. The estimates in columns three and four of Table 4 and the estimates in the final two columns of Table 5 do

\footnotetext{
${ }^{22}$ Recall that $\epsilon_{\Pi}=\epsilon_{Q}+\epsilon_{V}-\epsilon_{F}$ and that $\epsilon_{Q}=\nu_{Q}+\eta$ and $\epsilon_{\Pi}=\nu_{\Pi}+r \eta$.
} 
not take account of correlation between the error terms in the entry and quantity equations, i.e. they do not take account of endogenous entry. All three of these specifications yield larger estimates of the effect of entry on quantity than does the main estimation, which takes account of endogenous entry. For example, compare the estimated effect of the entry of a second firm from the main estimation $\left(\delta_{2}\right)$ with estimates that do not account for endogenous entry. The estimate from the main estimation (column 2 of Table 5) is 0.25. The estimate in column 4 (No DFA), which does not account for endogeneity, is 0.46 . The estimates for the entry of a second firm from the single equation model (Table 4) are 0.48 and 0.62. Ignoring the endogeneity of entry in the quantity equation leads to overestimating the demand-increasing effects of entry and competition by the second firm by about $100 \%$.

\subsection{Ratios and Competition}

Table 6 contains the estimated per-firm population thresholds for a hypothetical market with all covariates at their mean values. We report per-firm entry threshold ratios in Table 7, along with their standard errors. ${ }^{23}$ The first two columns of Table 7 display the threshold ratios for the simple ordered probit model presented in Table 4. The third and fourth columns contain the threshold ratios from the full model of Table 5.

Since both the ordered probit and the full model provide consistent estimators of $\delta_{N}-$ $\alpha_{N}-\gamma_{N}$, the threshold ratios implied by these two models should be nearly identical, and they are. Recall that the simple ordered probit model is an estimate of equation 15, the first equation of the model. Single equation estimates of this equation are consistent. The disadvantage of the simple ordered probit is that it is not able to distinguish between $\delta, \alpha$, and $\gamma$. But for purposes of calculating threshold ratios there is no need to distinguish among these parameters, as can be seen from equation 19.

The estimates in Table 7 show that the second firm requires about twice the per-firm

\footnotetext{
${ }^{23}$ Here and elsewhere, standard errors for non-linear transformations of the parameters are calculated via the delta method.
} 
population as does the first firm. The third firm requires about $40 \%$ more per-firm population than does the second, and the fourth firm requires about the same per-firm population as does the third. The differences between the threshold ratios for the $2 / 1$ entry and the $2 / 3$ entry are statistically significant at 5\%, as are the differences between the $2 / 1$ and $3 / 4$ ratios. The differences between the $2 / 3$ and $3 / 4$ ratios are not significant, and the $3 / 4$ ratio is not significantly different from 1.

Assuming that fixed costs are constant in $N$, these point estimates show that the toughness of competition is no longer changing with entry after the third firm enters. If we interpret unchanging toughness of competition as the achievement of competitive results, then we conclude that three firms is enough to achieve a competitive market.

We explore this pattern further by using the information on the demand equation. Note that we must assume that fixed costs are unchanging in $N$ in order to make inferences from the threshold ratios alone about changes in the toughness of price competition. The results in Table 7 by themselves could result from fixed costs rising with $N$ at a decreasing rate without any change in competitive conditions.

The quantity results help to dispel this possibility. In Table 8 the threshold ratios are decomposed into a per-capita demand effect and a variable profits and fixed cost effect. The per-capita demand contribution to the $2 / 1$ threshold is 0.77 . This means that, were variable profits and fixed costs to remain the same when the second firm enters, so that only per-capita demand changes with entry, the second firm would require only $77 \%$ the per-firm market size that the first firm did. This is another way of saying that per-capita demand rises by about $23 \%$ with the entry of the second firm. Similarly, the ratio of fixed costs to variable profits rises by a factor of 2.54 with the entry of the second firm. The product of these two numbers yields the overall 2/1 threshold ratio from Table 7 of 1.95 . 


\section{Discussion}

Taken together, the entry and quantity results indicate that entry by the second firm both increases quantity and decreases average variable profits as a fraction of fixed costs. A reduction in price would do this. Similarly, the entry of the third firm increases quantity and reduces the ratio of average variable profits to fixed costs, which would also happen if a price decrease occurred. Both of these effects are statistically significant at conventional levels (see Table 5). The entry of the fourth firm, however, leads to a non-significant decline in demand and a non-significant increase in the ratio of average variable profits to fixed costs.

The importance of $\eta$ demonstrates that there is significant inter-market heterogeneity which leads the market structure dummies to be endogenous. In addition, the fact that $r$ is significantly less that one likely indicates that the toughness of price competition varies considerably among markets.

The model we use to structure our analysis makes several strong assumptions about the nature of competition in the markets we analyze. It assumes that we have properly defined the geographic market. It assumes that the firms play a game resulting in a symmetric equilibrium. These assumptions are not likely to be literally true for hospital markets, so we now turn to a discussion of potential problems, how we attempt to mitigate them, and what effects these problems might have on our estimates.

A long and voluminous line of research demonstrates that there is very substantial geographic differentiation among hospitals (see Capps et al., 2003; Gaynor and Vogt, 2003, 2000, and references therein). As we mentioned previously, our strategy in defining markets was designed to minimize this kind of differentiation. The hospitals in a market are all within five miles of each other and are separated from other hospitals by at least 15 miles.

In addition to geographic factors, hospitals have a variety of sizes, levels of technological sophistication, and reputation, and prior work demonstrates both that these factors influence demand and that the influence is different for different types of patients (Capps et al., 2003; 
Gaynor and Vogt, 2003, 2000, and references therein).

If these additional dimensions of differentiation are also important to demanders, then inference about the effects of entry is less clear. In differentiated products models, entry of a new firm can affect quantity both through its effect on price and by increasing product diversity. If entry is consumer welfare enhancing, then quantity will increase. If entry does not enhance consumer welfare, then quantity will not increase. As a consequence, if the product is differentiated, we may be able to make inferences about whether entry leads to consumer welfare enhancing changes in competition, but we will not be able infer the precise nature of the competitive mechanism.

With a differentiated product, however, it is possible that we may be overstating or understating the effects of entry on competition. It is likely that in a differentiated product model a first entrant will position itself in the most profitable niche, with later entrants filling in progressively less attractive niches. This could generate a generally declining entry threshold ratio pattern even in the absence of competitive effects, depending on the relative profitability of the niches. As Bresnahan and Reiss (1991) point out, it is very difficult to rule out product differentiation, especially along difficult to observe lines, as an explanation for the changing threshold ratios. However, as they also point out, one would not expect the ratios to converge to one with entry in the presence of product differentiation.

Previous work has detected effects of product differentiation on entry thresholds from within the BR framework. Bresnahan and Reiss (1991) analyzed, among other markets, the market for new car dealers. They found that the per-firm threshold ratio for the fourth firm was substantially above one and interpreted this as being generated by product differentiation among the dealers: the fourth entrant was usually a second GM dealership and was also the first intra-brand competitor. In a similar vein, Dranove et al. (2003) show in their analysis of HMO markets that the entry of successive HMOs into different market niches generates a nonmonotonic relationship between the number of entrants and the entry threshold ratios. By contrast, in our work the entry threshold ratios have exhibited a monotonic relationship with 
entry, and have robustly converged to around one by four entrants. ${ }^{24}$ Thus the patterns we find are not consistent with a hypothesis that entry leads to increased product differentiation with no increase in competition.

Another important assumption of the entry model is equal division of the market among the entrants. We examine how close to equal division our markets come. In Table 9, we show the distribution of the spread of bed sizes in our markets. ${ }^{25}$ The first few rows show the distribution of our raw dispersion measure, the number of beds in the biggest hospital in the market minus the number of beds in the smallest hospital in the market, divided by the total number of beds in the market. As is readily apparent, there is a non-trivial ex post difference in the output among hospitals in our markets. In the median duopoly market, the smaller hospital is smaller than the larger by $20 \%$ of the total beds in the market. In the median triopoly, the median bed spread is 0.25 and in four hospital markets, it is 0.33 .

If firms know before entering whether they are going to be large or small and if the smaller firms are not able to command higher prices (as seems likely in this industry), then destined-to-be-small firms, who will receive less than $\frac{1}{N}$ of market quantity, will presumably enter after the destined-to-be-big firms and will require a larger population increment to induce them to enter. While this could potentially explain the increasing per-firm thresholds we estimate, it can not explain the increasing per-capita demand. Furthermore, we do not believe that it can explain the pattern of threshold ratios we see in our data.

To address this, consider the following. Modify equation 15 to allow for heterogeneous firm sizes: simply replace $\frac{1}{N}$ by $\operatorname{share}_{N}$. Then, assuming that conduct and fixed costs do not change with entry, the per-firm threshold ratios would be $\frac{s_{N+1}}{s_{N}}=\frac{N \cdot \text { share }_{N}}{(N+1) \cdot \operatorname{share}_{N+1}}$. The quantity $N \cdot$ share $_{N}$ is the $N^{\text {th }}$ firm's share as a proportion of what its share would be under equal division $\left(\frac{1}{N}\right)$.

\footnotetext{
${ }^{24}$ In some earlier drafts of this paper, even three firms appeared to be enough to generate a unit entry threshold ratio.

${ }^{25}$ As we indicated in Section 3, capacity is highly correlated with other measures of hospital output.
} 
The second section of Table 9 contains information on the distribution of $N$ times the bed share of the smallest firm in each of our non-monopoly markets. If firms are of equal size, this measure equals one. Further, it measures proportionately how much smaller the smallest firm is, compared to how large it would be under equal shares. The table says that in the median duopoly market, the smaller firm is $79 \%$ of the size ( $21 \%$ smaller) it would be under equal shares. Similarly, in the median triopoly and four firm markets the smallest firms are $60 \%$ and $41 \%$ of the sizes they would be under equal division.

Having constructed these measures, now consider the hypothesis that all of the movement in threshold ratios comes from size effects and that there is no effect of entry on competition. Then, as we discuss above, the threshold ratios would be $\frac{1}{0.79}=1.27$ for the $2 / 1$ threshold,

$\frac{0.79}{0.60}=1.32$ for the $3 / 2$ threshold, and $\frac{0.60}{0.40}=1.5$ for the $4 / 3$ threshold. These ratios increase in $N$, whereas our estimates decrease. Furthermore, the differences among these thresholds are small relative to the differences between our estimated thresholds. Thus, although the firms in our sample do have heterogeneous sizes, this heterogeneity does not change very much with increasing $N$ and, to the extent it does change, it changes in the opposite direction of what would be necessary to explain away our entry threshold results.

\section{Summary and Conclusions}

The relationship between market structure and competition is central to industrial organization. In this paper we augment the empirical approach developed by Bresnahan and Reiss for industries where there are good data available on quantity in addition to market structure.

We use this approach to examine the relationship between market structure and competition in hospital markets. This approach is particularly valuable in examining competition in these markets. Hospital prices are measured poorly in available data. As a consequence, an approach to assessing competition which does not rely on price data is valuable. In addi- 
tion, with our approach we are able to assess whether this competition is consumer welfare increasing and pinpoint the effects of changes in the number of firms in small markets, neither of which is possible from the earlier structure-conduct-performance based literature on hospital competition.

We find evidence that entry leads to a significant increase in competition in the hospital markets we examine. This corroborates the results from price-based studies of hospital competition. In addition, we find that competition increases consumer welfare. Interestingly enough, most of the effect on competition comes from the entry of a second and third hospital. Subsequent entry has a much smaller estimated effect on competition.

Since the U.S. health care system is primarily market-based, effective competition in these markets is critical. Antitrust authorities have opposed hospital mergers where they have felt they would be anticompetitive. The courts in recent years have rejected these attempts to block hospital mergers.

The policy prescription from our work is that the antitrust enforcement agencies should be particularly concerned about merger to monopoly or duopoly in isolated, rural hospital markets like the ones we analyze. This is relevant, since quite a few recent hospital mergers have had this character.

Three out of the 11 hospital merger cases that the U.S. antitrust enforcement agencies have brought in the last twenty years were in markets in our sample. ${ }^{26}$ The mergers in each of these cases reduced the number of hospitals from 3 to 2 . Our estimates imply substantial reductions in competition from these mergers, and a reduction in consumer welfare. Our estimates of the entry threshold ratios indicate that the third firm in a market requires a $41 \%$ larger population per-firm to support it than does the second firm (Table 6), implying a substantial increase in competition due to the entry of a third firm. Further, per-capita

\footnotetext{
${ }^{26}$ Poplar Bluff, Missouri (FTC et al v. Tenet Healthcare Corporation, et al, 186 F.3d 1045 (8th Cir, 1999)), Ukiah, California (Adventist Health System/West (117 FTC 23, 1994)), Dubuque, Iowa (U.S. v. Mercy Health Services and Finley Tri-States Health Group, Inc. (902 F. Supp. 968, N.D. IO, 1995)). See Gaynor and Vogt (2000) for more details.
} 
demand increases about $15 \%$ due to the entry of a third firm (Table 7), implying an increase in consumer welfare. Some of the other cases have involved merger to monopoly. ${ }^{27}$ The anticompetitive effects of such mergers could be even greater. Mergers that reduce the number of hospitals from from four to three have, on average, lesser effects on competition. ${ }^{28}$

\footnotetext{
${ }^{27}$ For example, Grand Rapids, Michigan (FTC vs. Butterworth Health Corporation and Blodgett Memorial Medical Center (1996, 947 F. Supp. 1285)).

${ }^{28}$ Our results indicate that on average for the markets we study here, entry of a fourth firm has little effect on competition. Of course this is subject to the caveat that antitrust effects are specific to the particulars of a market. Thus a merger reducing the number of firms from four to three could be anticompetitive for any particular market.
} 


\section{References}

American Hospital Association (1990). American Hospital Association Guide to the Health Care Field. American Hospital Association, Chicago, IL.

Berry, S. T. (1992). Estimation of a model of entry in the airline industry. Econometrica, 60:889-917.

Berry, S. T., Levinsohn, J., and Pakes, A. (1998). Differentiated products demand systems from a combination of micro and macro data: the new car market. unpublished paper, Yale University.

Berry, S. T. and Waldfogel, J. (1999). Free entry and social inefficiency in radio broadcasting. Rand Journal of Economics, 30:397-420.

Bresnahan, T. (1989). Empirical studies of industries with market power. In Schmalensee, R. and Willig, R. D., editors, Handbook of industrial organization, volume 2, pages 1011-1057. Elsevier Science, New York.

Bresnahan, T. and Reiss, P. (1988). Do entry conditions vary across markets? Brookings Papers on Economic Activity, 3:833-882.

Bresnahan, T. and Reiss, P. (1991). Entry and competition in concentrated markets. Journal of Political Economy, 99:977-1009.

Bureau of Health Professions (1996). Area Resource File. prepared for the Bureau of Health Professions by Applied Management Sciences. available through the National Technical Information Service.

Capps, C., Dranove, D., and Satterthwaite, M. (2003). Competition and market power in option demand markets. Rand Journal of Economics, 34(4):737-63. 
Connor, R. A., Feldman, R. D., and Dowd, B. E. (1998). The effects of market concentration and horizontal mergers on hospital costs and prices. International Journal of the Economics of Business, 5:159-180.

Davis, P. J. (2002). Entry, cannibalization and bankruptcy in the U.S. motion picture exhibition market. unpublished paper, Sloan School, MIT.

Dranove, D., Gron, A., and Mazzeo, M. J. (2003). Differentiation and competition in hmo markets. Journal of Industrial Economics, 51(4):433-454.

Dranove, D. D. and Ludwick, R. (1999). Competition and pricing by nonprofit hospitals: a reassessment of Lynk's analysis. Journal of Health Economics, 18(1):87-98.

Dranove, D. D. and Satterthwaite, M. A. (2000). The industrial organization of health care markets. In Culyer, A. and Newhouse, J., editors, Handbook of Health Economics, chapter 20, pages 1094-1139. Elsevier Science, B.V., Amsterdam.

Dranove, D. D., Shanley, M., and Simon, C. (1992). Is hospital competition wasteful? Rand Journal of Economics, 23:247-262.

Dranove, D. D., Shanley, M., and White, W. D. (1993). Price and concentration in hospital markets: the switch from patient-driven to payer-driven competition. Journal of Law and Economics, 36:179-203.

Dranove, D. D. and White, W. D. (1994). Recent theory and evidence on competition in hospital markets. Journal of Economics and Management Strategy, 3:169-209.

Feldman, R. and Dowd, B. (1986). Is there a competitive market for hospital services? Journal of Health Economics, 5(3):277-92.

Frech, III, H. E. (1987). Comments on (hospital) antitrust issues. Advances in Health Economics and Health Services Research, 7:853-872. 
Gaynor, M. and Vogt, W. B. (2000). Antitrust and competition in health care markets. In Culyer, A. J. and Newhouse, J. P., editors, Handbook of Health Economics, volume 1B, chapter 27, pages 1405-1487. Elsevier Science B.V., Amsterdam.

Gaynor, M. and Vogt, W. B. (2003). Competition among hospitals. Rand Journal of Economics, 34(4):764-85.

Genesove, D. (2004). Why are there so few (and fewer and fewer) two-newspaper towns? unpublished paper, Hebrew University of Jerusalem.

Heckman, J. and Singer, B. (1984). A method for minimizing the impact of distributional assumptions in econometric models for duration data. Econometrica, 52:271-320.

InterStudy (1990). InterStudy National HMO Census. InterStudy, Excelsior, MN.

Jaklevic, M. C. (2002). Tired trend. Modern Healthcare, 32(26):10.

Joskow, P. L. (1980). The effects of competition and regulation on hospital bed supply and the reservation quality of the hospital. Bell Journal of Economics, 11(2):421-47.

Kessler, D. and McClellan, M. (2000). Is hospital competition socially wasteful? Quarterly Journal of Economics, 115(2):577-615.

Krishnan, R. (2001). Market restructuring and pricing in the hospital industry. Journal of Health Economics, 20:213-239.

Lesser, C. S. and Ginsburg, P. B. (2001). Back to the future? new cost and access challenges emerge: initial findings from HSC's recent site visits, Issue Brief \#35. Center for Studying Health Systems Change, Washington, DC.

Lynk, W. J. (1995). Nonprofit hospital mergers and the exercise of market power. Journal of Law and Economics, 38:437-61. 
Lynk, W. J. and Neumann, L. R. (1999). Price and profit. Journal of Health Economics, 18:99-105.

Mankiw, N. G. and Whinston, M. D. (1986). Free entry and social inefficiency. Rand Journal of Economics, 17:48-58.

Manning, W. G., Newhouse, J. P., Duan, N., Keeler, E. B., and Leibowitz, A. (1987). Health insurance and the demand for medical care: evidence from a randomized experiment. American Economic Review, 77(3):251-77.

Mazzeo, M. J. (2002). Product choice and oligopoly market structure. Rand Journal of Economics, 33(2):221-242.

Mroz, T. (1999). Discrete factor approximations in simultaneous equations models: estimating the impact of a dummy endogenous variable on a continuous outcome. Journal of Econometrics, 92(2):233-74.

Mroz, T. and Guilkey, D. (1992). Discrete factor approximations for use in simultaneous equation models with both continuous and discrete endogenous variables. unpublished paper, Department of Economics, University of North Carolina, Chapel Hill.

Piper, T. (1998). Documentation on Certificate of Need Programs in United States for 1990. tabulated by State of Missouri Certificate of Need Program.

Schmalensee, R. (1989). Inter-industry studies of structure and performance. In Schmalensee, R. and Willig, R. D., editors, Handbook of industrial organization, volume 2, pages 9511009. Elsevier Science, New York.

Scott Morton, F. M. (1999). Entry decisions in the generic pharmaceutical industry. Rand Journal of Economics, 30:421-440.

Sutton, J. (1991). Sunk Costs and Market Structure. MIT Press. 
Volpp, K. and Waldfogel, J. (2000). Competition and the quality of hospital care: heart attack mortality after the onset of price competition in New Jersey. unpublished paper, University of Pennsylvania. 
Table 1: Sample Hospitals

\begin{tabular}{rrrrr} 
& \multicolumn{2}{c}{ Sample Hosps } & \multicolumn{2}{c}{ US Hosps } \\
Beds & Count & Percent & Count & Percent \\
\hline \hline$<10$ & 0 & 0.0 & 13 & 0.2 \\
$10-25$ & 1 & 0.2 & 307 & 5.6 \\
$26-50$ & 5 & 1.0 & 986 & 17.8 \\
$51-100$ & 176 & 35.9 & 1213 & 21.9 \\
$101-200$ & 195 & 39.8 & 1269 & 22.9 \\
$201-300$ & 63 & 12.9 & 744 & 13.5 \\
$301-400$ & 30 & 6.1 & 425 & 7.7 \\
$>400$ & 20 & 4.1 & 574 & 10.4
\end{tabular}


Table 2: Market Structure and Population

\begin{tabular}{ccc} 
Hospitals in Market & Number of Markets & Average Population \\
\hline \hline 0 & 205 & 9,562 \\
1 & 346 & 19,004 \\
2 & 49 & 51,930 \\
3 & 8 & 70,379 \\
$4+$ & 5 & 114,087
\end{tabular}


Table 3: Variable Definitions and Descriptive Statistics

\begin{tabular}{|c|c|c|c|}
\hline Variable Name & Definition & Mean & Std Dev \\
\hline Quantity & Adjusted admissions, market (1000s) & 5.50 & 7.82 \\
\hline Market population & City population $(100,000 \mathrm{~s})$ & 0.20 & 0.20 \\
\hline Fringe population & Non-city population within 15 miles $(100,000 s)$ & 0.16 & 0.13 \\
\hline Commuters & Proportion commuting $45+\min$ to work & 0.06 & 0.03 \\
\hline Proportion $65+$ & Proportion of city population age $65+$ & 0.17 & 0.05 \\
\hline \# HMOs & \# HMOs in county & 0.96 & 1.56 \\
\hline Per-capita income & City per-capita income $(\$ 1000$ s $)$ & 10.77 & 2.21 \\
\hline $\mathrm{CON}$ & Dummy for state certificate of need law & 0.56 & \\
\hline Wage index & CMS wage index (base $=1$ ) & 0.80 & 0.08 \\
\hline Rent & City median gross rent $(\$ 1000 \mathrm{~s})$ & 0.31 & 0.07 \\
\hline Construction cost & Adjusted CMS construction cost index (base $=1)$ & 0.88 & 0.10 \\
\hline Distance $\rightarrow$ big & Distance to place with pop. $>100 \mathrm{~K}(100$ s miles $)$ & 1.02 & 0.15 \\
\hline Distance $\rightarrow$ small & Distance to place with pop. $>5 \mathrm{~K}$ (100s miles) & 0.29 & 0.15 \\
\hline Military base & Dummy for military base $>500$ employees & 0.04 & \\
\hline
\end{tabular}


Table 4: Single equation estimates

\begin{tabular}{|c|c|c|c|}
\hline \multirow[b]{2}{*}{ Variable } & $N$ & \multirow{2}{*}{$\begin{array}{l}\ln Q \\
\text { OLS }\end{array}$} & \multirow{2}{*}{$\begin{array}{c}\ln Q \\
\text { Selection }\end{array}$} \\
\hline & ordered probit & & \\
\hline \multirow[t]{2}{*}{ constant } & 0.92 & 8.38 & 8.55 \\
\hline & $(0.08)$ & $(0.03)$ & $(0.03)$ \\
\hline \multirow[t]{2}{*}{ Market Population } & 2.24 & 0.68 & 0.46 \\
\hline & $(0.16)$ & $(0.06)$ & $(0.06)$ \\
\hline \multirow[t]{2}{*}{ Fringe Population } & 0.46 & 0.21 & 0.13 \\
\hline & $(0.09)$ & $(0.04)$ & $(0.04)$ \\
\hline \multirow[t]{2}{*}{ Military Base } & 0.77 & -0.10 & -0.17 \\
\hline & $(0.29)$ & $(0.11)$ & $(0.11)$ \\
\hline \multirow[t]{2}{*}{ Wage index } & -3.22 & -0.17 & 0.17 \\
\hline & $(0.99)$ & $(0.33)$ & $(0.33)$ \\
\hline \multirow[t]{2}{*}{ Rent } & -0.81 & -0.24 & -0.15 \\
\hline & $(0.50)$ & $(0.20)$ & $(0.20)$ \\
\hline \multirow[t]{2}{*}{ Income per capita } & 0.32 & 0.37 & 0.37 \\
\hline & $(0.46)$ & $(0.18)$ & $(0.18)$ \\
\hline \multirow[t]{2}{*}{ Number of HMOs } & -0.05 & -0.02 & -0.01 \\
\hline & $(0.04)$ & $(0.02)$ & $(0.02)$ \\
\hline \multirow[t]{2}{*}{ Proportion $65+$} & 0.90 & 0.11 & 0.01 \\
\hline & $(0.24)$ & $(0.10)$ & $(0.10)$ \\
\hline \multirow[t]{2}{*}{ Distance $\rightarrow$ big } & -0.07 & -0.05 & -0.03 \\
\hline & $(0.16)$ & $(0.07)$ & $(0.07)$ \\
\hline \multirow[t]{2}{*}{ Distance $\rightarrow$ small } & -0.03 & 0.14 & 0.06 \\
\hline & $(0.13)$ & $(0.08)$ & $(0.08)$ \\
\hline \multirow[t]{2}{*}{ Commuters } & -0.24 & -0.05 & -0.00 \\
\hline & $(0.12)$ & $(0.05)$ & $(0.05)$ \\
\hline
\end{tabular}


Table 4: Single equation estimates

\begin{tabular}{lrcc} 
& \multicolumn{1}{c}{$N$} & $\ln Q$ & $\ln Q$ \\
Variable & ordered probit & OLS & Selection \\
\hline \hline Construction Cost & 0.96 & & \\
& $(0.71)$ & & \\
CON & -0.03 & & \\
& $(0.13)$ & & \\
2 firms & 2.53 & 0.48 & 0.62 \\
& $(0.15)$ & $(0.08)$ & $(0.09)$ \\
3 firms & 4.48 & 0.69 & 0.90 \\
& $(0.29)$ & $(0.18)$ & $(0.19)$ \\
$4+$ firms & 5.36 & 0.66 & 1.07 \\
& $(0.38)$ & $(0.23)$ & $(0.25)$
\end{tabular}


Table 5: Maximum Likelihood Parameter Estimates

\begin{tabular}{|c|c|c|c|c|}
\hline \multirow[b]{2}{*}{ Parameter } & \multicolumn{2}{|c|}{ Full Model } & \multicolumn{2}{|c|}{ No DFA } \\
\hline & Estimate & Std Error & Estimate & Std Error \\
\hline \multicolumn{5}{|l|}{ Market Size, $\lambda$} \\
\hline Market population & 0.831 & 0.039 & 0.710 & 0.051 \\
\hline Fringe population & 0.212 & 0.021 & 0.173 & 0.025 \\
\hline Military base & 0.046 & 0.062 & 0.093 & 0.070 \\
\hline \multicolumn{5}{|c|}{ Per Capita Quantity, $\delta$} \\
\hline constant & 8.342 & 0.035 & 8.380 & 2.735 \\
\hline Wage index & -0.241 & 0.235 & -0.086 & 0.329 \\
\hline Rent & -0.161 & 0.137 & -0.275 & 0.199 \\
\hline Income per capita & 0.376 & 0.118 & 0.379 & 0.181 \\
\hline Number of HMOs & -0.012 & 0.013 & -0.019 & 0.017 \\
\hline Proportion $65+$ & 0.019 & 0.070 & 0.140 & 0.097 \\
\hline Commuters & -0.041 & 0.032 & -0.043 & 0.050 \\
\hline Distance $\rightarrow$ big & -0.002 & 0.047 & -0.071 & 0.068 \\
\hline Distance $\rightarrow$ small & 0.215 & 0.051 & 0.108 & 0.074 \\
\hline$\delta_{2}$ & 0.254 & 0.059 & 0.463 & 0.083 \\
\hline$\delta_{3}$ & 0.415 & 0.130 & 0.201 & 0.176 \\
\hline$\delta_{4}$ & 0.297 & 0.152 & -0.110 & 0.264 \\
\hline
\end{tabular}


Table 5: Maximum Likelihood Parameter Estimates

\begin{tabular}{|c|c|c|c|c|}
\hline \multirow[b]{2}{*}{ Parameter } & \multicolumn{2}{|c|}{ Full Model } & \multicolumn{2}{|c|}{ No DFA } \\
\hline & Estimate & Std Error & Estimate & Std Error \\
\hline \multicolumn{3}{|c|}{ Variable Profits: demand shifters, $\alpha_{X}$} & & \\
\hline Income per capita & -0.254 & 0.209 & -0.271 & 0.236 \\
\hline Number of HMOs & -0.006 & 0.020 & 0.024 & 0.021 \\
\hline Proportion $65+$ & 0.134 & 0.103 & 0.140 & 0.116 \\
\hline Commuters & -0.054 & 0.055 & -0.038 & 0.064 \\
\hline Distance $\rightarrow$ big & -0.005 & 0.074 & 0.056 & 0.084 \\
\hline Distance $\rightarrow$ small & 0.053 & 0.075 & 0.103 & 0.087 \\
\hline \multicolumn{5}{|l|}{ Fixed Costs: $\gamma_{W}$} \\
\hline Construction cost & -0.315 & 0.270 & -0.278 & 0.229 \\
\hline $\mathrm{CON}$ & 0.027 & 0.047 & 0.017 & 0.041 \\
\hline \multicolumn{5}{|c|}{ Variable Profits \& Fixed costs: } \\
\hline \multicolumn{5}{|c|}{ Cost shifters, $\gamma_{W}-\alpha_{W}$} \\
\hline constant & 7.997 & 0.046 & 8.084 & 0.044 \\
\hline Wage index & 0.977 & 0.438 & 0.947 & 0.466 \\
\hline Rent & 0.110 & 0.227 & -0.024 & 0.254 \\
\hline \multicolumn{5}{|c|}{ Entry effects: $\gamma_{N}-\alpha_{N}$} \\
\hline$\gamma_{2}-\alpha_{2}$ & 0.871 & 0.077 & 1.578 & 0.093 \\
\hline$\gamma_{3}-\alpha_{3}$ & 1.344 & 0.156 & 0.817 & 0.192 \\
\hline$\gamma_{4}-\alpha_{4}$ & 1.251 & 0.186 & -0.110 & 0.264 \\
\hline
\end{tabular}


Table 5: Maximum Likelihood Parameter Estimates

\begin{tabular}{|c|c|c|c|c|}
\hline \multirow[b]{2}{*}{ Parameter } & \multicolumn{2}{|c|}{ Full Model } & \multicolumn{2}{|c|}{ No DFA } \\
\hline & Estimate & Std Error & Estimate & Std Error \\
\hline Error distributions & & & & \\
\hline$p_{1}$ & 0.005 & 0.005 & & \\
\hline$p_{2}$ & 0.004 & 0.004 & & \\
\hline$p_{3}$ & 0.003 & 0.005 & & \\
\hline$p_{4}$ & 0.007 & 0.006 & & \\
\hline$p_{5}$ & 0.644 & 0.079 & & \\
\hline$p_{6}$ & 0.336 & 0.079 & & \\
\hline$p_{7}$ & 0.002 & 0.002 & & \\
\hline$\beta_{1}$ & -4.845 & 0.243 & & \\
\hline$\beta_{2}$ & -3.513 & 0.242 & & \\
\hline$\beta_{3}$ & -1.918 & 0.362 & & \\
\hline$\beta_{4}$ & -1.476 & 0.249 & & \\
\hline$\beta_{5}$ & -0.093 & 0.045 & & \\
\hline$\beta_{6}$ & 0.336 & 0.061 & & \\
\hline$\beta_{7}$ & 1.563 & 0.252 & & \\
\hline$\sigma_{\nu_{\Pi}}$ & 0.372 & 0.027 & 0.325 & 0.030 \\
\hline$\sigma_{\nu_{Q}}$ & 0.236 & 0.017 & 0.455 & 0.016 \\
\hline$r$ & 0.230 & 0.073 & & \\
\hline$V(\eta)$ & 0.241 & 0.125 & & \\
\hline$V(r \eta)$ & 0.013 & 0.011 & & \\
\hline Number of Observations & & 613 & 613 & \\
\hline Log-Likelihood & & -467.29 & -588.84 & \\
\hline
\end{tabular}


Table 6: Per-Firm Population Thresholds

Number of Hospitals Threshold Std Error

1

$6,988 \quad 203$

2

$12,616 \quad 682$

3

$19,145 \quad 1,688$

$4+$

19,861

2,449 
Table 7: Threshold Ratios

\begin{tabular}{ccccc} 
Ratio & \multicolumn{2}{c}{ Ordered Probit } & \multicolumn{2}{c}{ Full Model } \\
& Estimate & Std Error & Estimate & Std Error \\
\hline \hline & & & & \\
$s_{2} / s_{1}$ & 1.97 & 0.12 & 1.95 & 0.12 \\
$s_{3} / s_{2}$ & 1.44 & 0.13 & 1.41 & 0.12 \\
$s_{4} / s_{3}$ & 1.06 & 0.12 & 1.04 & 0.11
\end{tabular}


Table 8: Threshold Ratios' Decomposition

\begin{tabular}{lcccc} 
Component & & $2 / 1$ & $3 / 2$ & $4+/ 3$ \\
\hline \hline & & & & \\
Per-Capita Q & $d_{N+1} / d_{N}$ & 0.77 & 0.85 & 1.13 \\
Fixed Cost \& Profit & $\frac{V_{N}}{V_{N+1}} \frac{F_{N+1}}{F_{N}}$ & 2.54 & 1.66 & 0.92 \\
& & & & \\
Overall & $s_{N+1} / s_{N}$ & 1.95 & 1.41 & 1.04
\end{tabular}


Table 9: Size dispersion within markets

Percentile 2 hospitals 3 hospitals 4 hospitals

\section{Spread of beds}

$\begin{array}{llll}10 \text { th } & 0.05 & 0.10 & 0.21 \\ 25 \text { th } & 0.09 & 0.17 & 0.24 \\ \text { median } & 0.21 & 0.25 & 0.33 \\ 75 \text { th } & 0.38 & 0.38 & 0.45 \\ 90 \text { th } & 0.60 & 0.49 & 0.52\end{array}$

$N$ times share of smallest

$\begin{array}{lrrr}10 \text { th } & 0.43 & 0.29 & 0.32 \\ 25 \text { th } & 0.62 & 0.46 & 0.35 \\ \text { median } & 0.79 & 0.60 & 0.41 \\ 75 \text { th } & 0.91 & 0.76 & 0.56 \\ 90 \text { th } & 0.95 & 0.89 & 0.69 \\ \text { Number of Markets } & 49 & 8 & 4\end{array}$




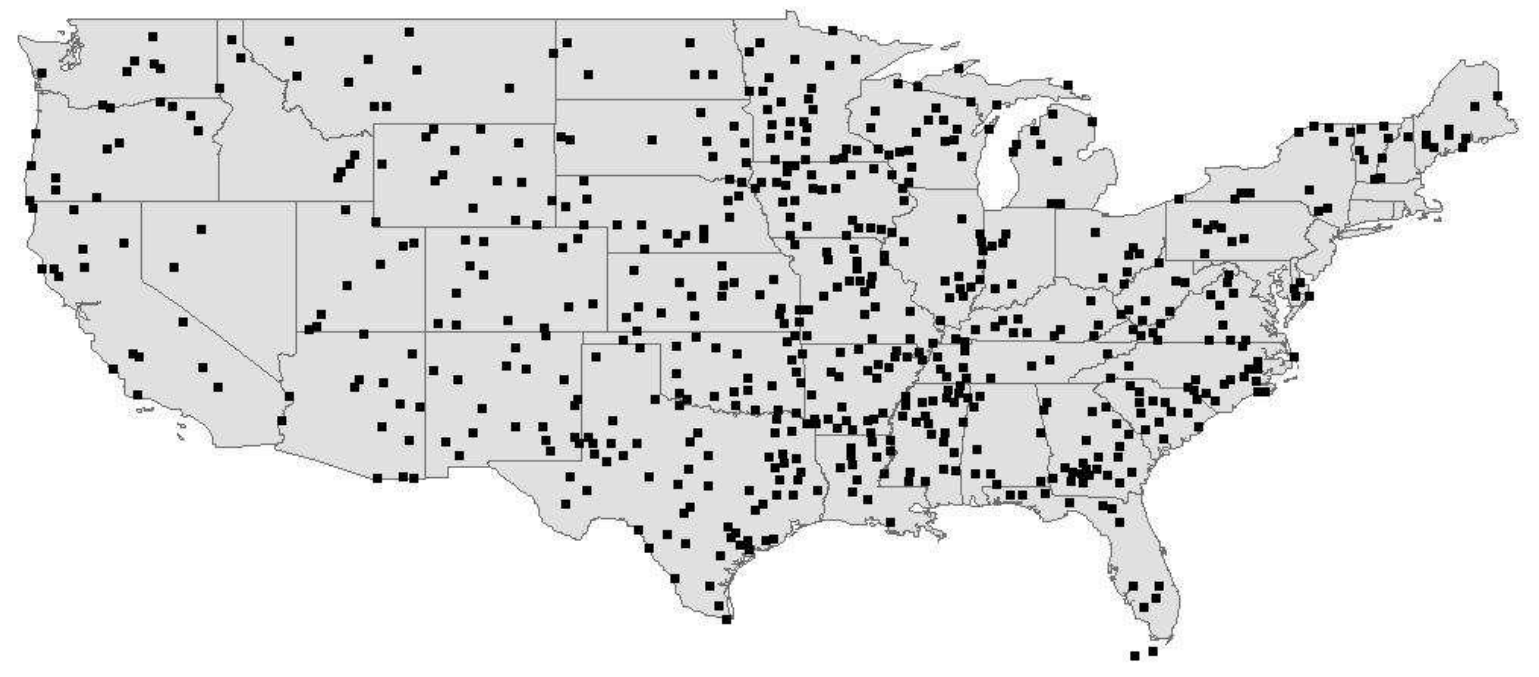

Figure 1: Geographical Distribution of Hospital Markets 